\title{
History of the LIME Network and the development of Indigenous health in medical education
}

\begin{abstract}
The Leaders in Indigenous Medical Education (LIME) Network has developed over time as an avenue for sharing, developing and improving upon the emerging discipline of Indigenous health in medical education
\end{abstract}

\section{he Leaders in Indigenous Medical Education (LIME) Network (a program of Medical Deans . ustralia and New Zealand, funded by the} Australian Government Department of Health and Ageing [DoHA]) has an 800-strong membership of Indigenous and non-Indigenous medical educators, health educators, university leaders, health practitioners, policymakers and community members concerned with improving health outcomes for Indigenous people. The Network encourages and supports collaboration within and between medical schools in Australia and Aotearoa/New Zealand to enhance the quality and effectiveness of Indigenous health curricula in medical education and to enable best practice in the recruitment and retention of Indigenous medical students. Over time, it has developed a portfolio of work that provides quality review, professional development, capacity-building, research and advocacy functions for Network members, and has developed links with specialist medical colleges and educators from other health disciplines. The Network is founded on Indigenous leadership and celebrates the many successes that are occurring in the field of Indigenous health and medical education.

\section{Background}

Historically, the relationship between Indigenous peoples and the medical fraternity has had its challenges. In Australia, doctors were involved in implementing segregation policies and played a role in the removal of Aboriginal children from their families. ${ }^{1}$ Over time, and in recognition of the role of Aboriginal and Torres Strait Islanders in informing government policies and initiatives, researchers and medical practitioners began to acknowledge the special place of Aboriginal and Torres Strait Islander people in the health system. $^{1-6}$

The status of Indigenous peoples' health in Australia and Aotearoa/New Zealand remains well below that of their nonIndigenous counterparts. ${ }^{7-9}$ While there is a range of historical, social and economic factors that influence these figures, the quality of care provided to Indigenous peoples is also an important factor requiring attention. ${ }^{10}$ The institutions that educate future medical professionals, therefore, have an important responsibility in developing a workforce that is responsive to the needs of Indigenous people. ${ }^{11-13}$

\section{Joining forces: an informal network for Indigenous health}

While formally recognised in 2005, the collaborative effort that underpins the LIME Network has a longer history. In the 1980s, the need for specific training in Indigenous health in medical education was formally submitted for the first time in Australia as part of the Inquiry into Medical Education and Medical Workforce (Ian Anderson, Professor and Foundation Chair of Indigenous Higher Education, University of Melbourne, personal communication). ${ }^{14}$ Publications on the importance of acknowledging the place of Aboriginal people in the Australian health care system were increasing ${ }^{15,16}$ and the first Aboriginal and Torres Strait Islander medical student recruitment programs were being implemented at sites across Australia (Shannon C, Leon D, Report on the LIME Workshop, 8-10 June 2005, Freemantle). ${ }^{17,18}$ Recommendations from health conferences increasingly emphasised the need to build an appropriate health workforce and include Indigenous health in education and training. 1,19,20

Importantly, in March 1997, the Inaugural Indigenous Graduate and Undergraduate Medical Conference was held at Salamander Bay, New South Wales, followed closely by the Second Indigenous Medical Conference in July that same year (Garvey G, Smith S, Proceedings of the Inaugural Indigenous Graduate and Undergraduate Medical Conference, 31 March - 3 April 1997, Salamander Shores; Garvey G, Smith S, Proceedings of the Second Indigenous Medical Conference, 14-16 July 1997, Salamander Shores).

Convened by the University of Newcastle, and funded by the Australian Government's Office for Aboriginal and Torres Strait Islander Health (OATSIH), these conferences led to the establishment of the Australian Indigenous Doctors' Association (AIDA), which was formalised in 1998. Further goals and recommendations of these conferences that are pertinent to the LIME Network objectives today included that:

- the deans of medical schools make a commitment to increasing content on and awareness of Indigenous issues in medical curricula;

doi: 10.5694/mjal3.10403 - teaching of Indigenous health be embedded throughout medical curricula;

- consultation with and participation of Indigenous academics and people in the teaching process is essential; and - the number of Indigenous students entering medicine should increase (University of Newcastle, Recommendations to the Medical Deans meeting arising from the Second Indigenous Medical Conference, 29 August 1997, Perth).

These and other recommendations were presented by Aboriginal and Torres Strait Islander doctors, academics and medical students to a Committee of Deans of Australian 


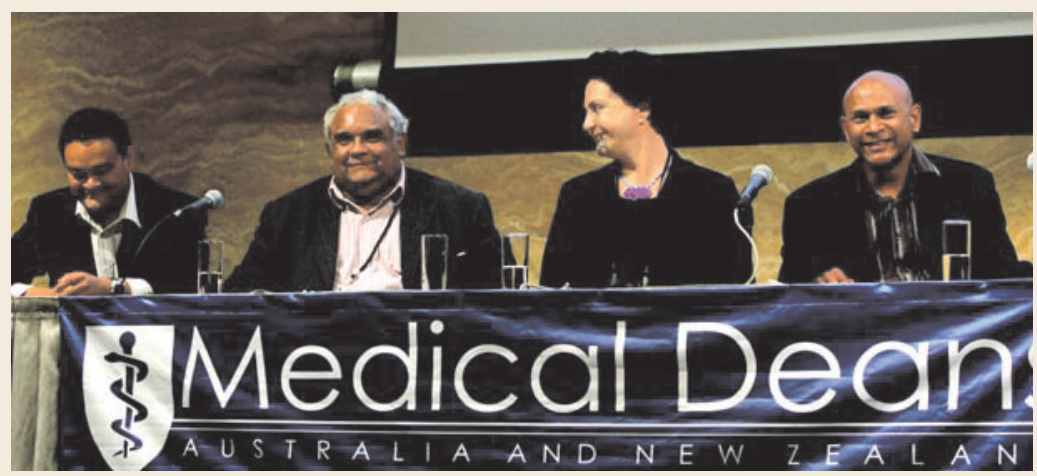

Associate Professor Kelvin Kong, Dr Tom Calma, Associate Professor Papaarangi Reid, Dr Mark Wenitong, at LIME Connection II, Sydney, 2007.

Medical Schools (CDAMS, now Medical Deans Australia and New Zealand) meeting in Perth in August 1997, and were subsequently endorsed. The need for significant and effective Indigenous consultation and leadership as a fundamental element of any successful policy or program in Indigenous health was also acknowledged. ${ }^{21}$

\section{A national curriculum and formalisation of the LIME Network}

Following the CDAMS endorsement of the recommendations described above, two national reviews of Indigenous health in medical education were conducted - one by the Australian National Audit Office on behalf of the Department of Health and Aged Care, ${ }^{22}$ and one by Gail Garvey and Ngiare Brown from the University of Newcastle. ${ }^{21}$ Both reviews identified a lack of consistency and a scattered approach to the inclusion of Indigenous health in the core medical curriculum and the methods used to recruit Indigenous Australians to study medicine.

As a response to the review findings, in November 1999, representatives from CDAMS and OATSIH and Indigenous medical educators from a number of universities came together to develop a strategy for Indigenous medical education with a twofold focus: workforce (recruitment and retention of Aboriginal people) and curriculum (Ian Anderson, personal communication). A series of meetings was initiated to develop core Indigenous health curricula and a collaborative process for ongoing national oversight to ensure that Indigenous health became a meaningful and sustainable component of medical education. ${ }^{23,24}$

In 2003, the Indigenous Health Curriculum Project was formalised through a partnership between CDAMS and OATSIH. The Project was hosted by the University of Melbourne's VicHealth Koori Health Research and Community Development Unit (which was later renamed the Onemda VicHealth Koori Health Unit) under the leadership of Ian Anderson, and Gregory Phillips was employed the National Program Manager. The National Curricula Workshop, held in August 2003 in Victor Harbor, South Australia, brought together leaders engaged in Indigenous health and medical education from around the country to engage in the Project's objectives:
The LIME

Connection provide opportunities to share make connections and gather evidence on best-practice approaches

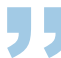
conferences...

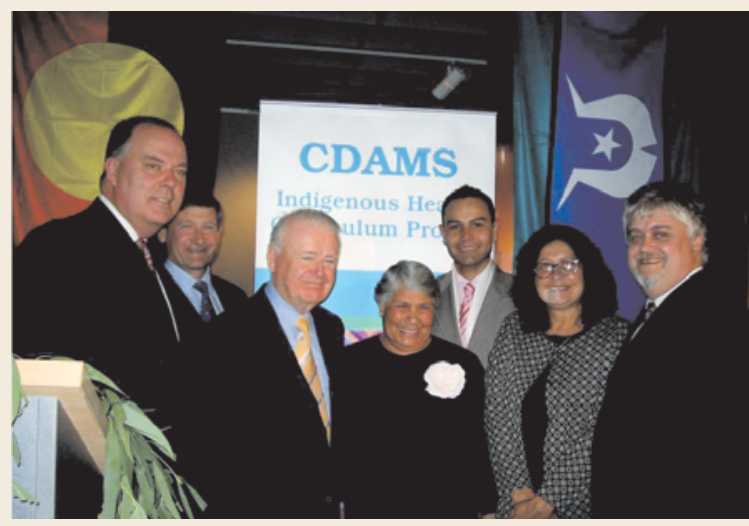

Launch of the CDAMS Indigenous Health Curriculum Framework, Melbourne, 2004 - (left to right) Professor S Bruce Dowton, Professor James Angus, Sir Willam Deane, Dr Lowitja O'Donoghue, Mr Gregory Phillips, Aunty Joy Murphy Wandin and Professor lan Anderson).

[The] meeting ... in Victor Harbor ... helped the leadership in medical schools, giving them a sense that "this is a safe place"

- Ian Anderson

James Angus OA (Professor and Dean, Faculty of Medicine, Dentistry and Health Sciences, University of Melbourne), who attended the meeting on behalf of CDAMS, reflected: innovations,

I knew there was a possibility of this taking off, because there was leadership, there was interest, there was passion.

An audit of all existing Indigenous health curricula in Australian medical schools followed ${ }^{25}$ and, in the process, the formal cooperation and collaboration between medical schools, CDAMS and the Project team began:

The audit was the first thing. That's how we engaged the people. Basically, people needed to be heard. They were struggling all by themselves in these institutions, often one Aboriginal worker or part-time worker expected to do everything themselves, and they were struggling. So the first thing was just being there and talking to them all and giving voice to their concerns.

— Gregory Phillips

The audit findings led to and informed the development of The CDAMS Indigenous Health Curriculum Framework. ${ }^{26}$ The Framework was officially launched in August 2004, with the endorsement of CDAMS representing deans from every medical school in Australia:

We had this wonderful ceremony where we launched the curriculum ... Sir William [Deane] made the point that he found it truly amazing that all the deans could agree on this core piece of curriculum that would be taught in every medical school in the country because, in his experience, academic professional groups can never agree on what is core.

\section{— James Angus}

The Framework provided medical schools with guidelines for developing and delivering Indigenous health content in core medical curricula. Following a determined effort by 


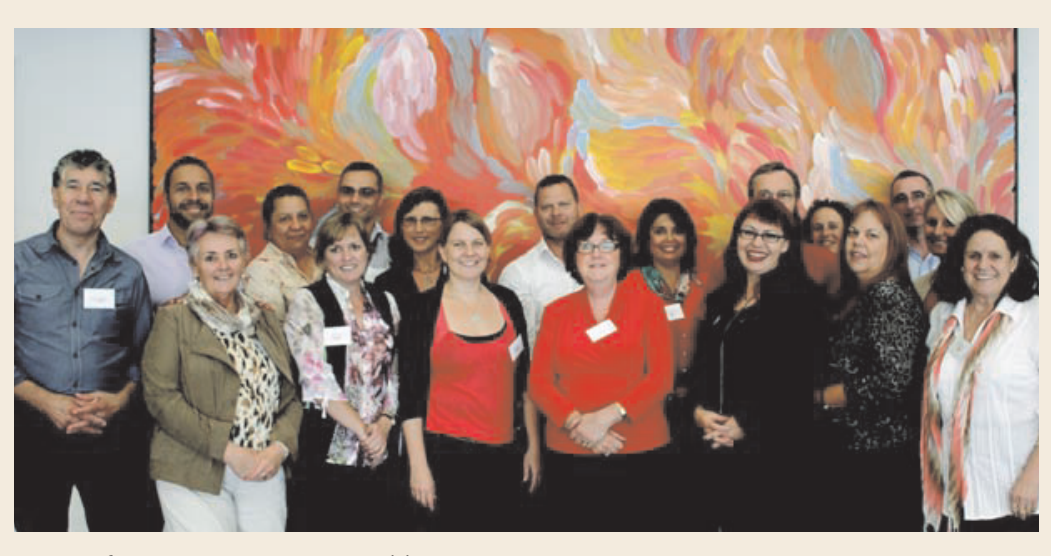

LIME Reference Group meeting, Gold Coast, 2012.
- professional development, capacity building and support;

- promoting best practice and building an evidence base through research and evaluation;

- professionalising the discipline;

- multidisciplinary and multisectoral networking;

- advocacy and reform; and

- hosting the LIME Connection conferences.

At the heart of the Network is the LIME Reference Group of medical educators, comprising Indigenous and non-Indigenous representatives from every medical school in Australia and Aotearoa/New Zealand. The LIME Steering Committee - made up of medical school deans and representatives from AIDA, Te ORA (Maori Medical Practitioners Association), the National Aboriginal Community Controlled Health Organisation, Indigenous Allied Health Australia, the Committee of Presidents of Medical Colleges and DoHA — ensures input, communication and partnerships with key representative bodies.

The LIME Network has been pivotal, over a sustained period, in strengthening the connections within and between universities and individuals dedicated to ensuring the quality and effectiveness of teaching and learning of Indigenous health in medical education and best practice in the recruitment and retention of Indigenous medical students:

LIME gives us a language in which to speak with one another. It is about us and what we do collectively to grow. It provides a beautiful, strong and congruent environment that supports communication and brings a focus to the bigger picture.

— Lisa Jackson Pulver AM, Professor and Director of the Muru Marri Indigenous Health Unit, University of New South Wales, and LIME Network Reference Group Member

The materials and resources developed as part of the Network's program of work contribute to the quality and rigour of Indigenous health teaching and learning and provide a forum for peer mentoring and participant support.

[W] are learning from other people's lessons and talking to others who totally understand the hard decisions that we have to make. Also more and more now, we are collaborating on research in areas of teaching and learning, Indigenous health and growing the workforce - it has become part of improving each other's academic practice.

- Papaarangi Reid, Associate Professor, Tumuaki/Deputy Dean and Head of the Department of Maori Health, Faculty of Medical and Health Sciences, University of Auckland, and LIME Network Steering Committee Member

The LIME Connection conferences have become a flagship of the Network's activities and have been held biennially since 2005. Attracting educators, students and professionals, primarily from the field of medicine, they provide opportunities to share innovations, make connections and gather evidence on best-practice approaches from around the world. Importantly, 
outstanding work by medical educators is celebrated through the LIMElight Awards.

Coming to the first LIME conference helped me understand that there were other Indigenous/non-Indigenous colleagues facing the same challenges as me. It was like an awakening to go from feeling so isolated to understanding you had a place in a community. LIME Connection gives us the opportunity to learn and further develop our work in a supportive environment.

- Suzanne Pitama, Associate Dean of the Maori/ Indigenous Health Institute, University of Otago, Christchurch, and LIME Network Reference Group Member

\section{Conclusion}

The LIME Network has developed over time to be a significant avenue through which information about Indigenous health and medical education can be shared, developed and improved upon.

It is not just one or two schools. It's old, new, rural and urban schools. There is a non-competitive nature to the sharing. We are working hard to support each other's work. The buy in from so many schools across both countries over a long period of time is exceptional.

\section{- Shaun Ewen}

The CDAMS Indigenous Health Curriculum Framework is being widely utilised (not only in medicine, but in other health disciplines) and the quality review tools and evidencebased materials developed as part of the LIME Network program $^{31,32}$ are ensuring that Indigenous health is developing as a discipline in its own right.

[The] Network is a wonderful enabler. It allows not only the connection, but it's a two way street, so that we've got a repository of the resources... [and] the outreach ... the knowledge gets shared and continues to advance. It's done in a very exciting, personally empowering, respectful and safe environment.

\section{— James Angus}

The leadership and support of Medical Deans Australia and New Zealand, AIDA and Te ORA, and the commitment and collegiality of medical educators involved, has been integral to the ongoing development of the LIME Network. We now see record numbers of Indigenous students enrolled in medicine ${ }^{33}$ and increased consistency and quality of Indigenous health teaching and learning in medicine. ${ }^{34}$

As an emerging field, Indigenous health is forging new approaches to education and training that will affect the way health care is understood and delivered. This will have implications not only for Indigenous patients, but for the community more broadly.

The goal of the network, the overall goal should be to empower people to make change, and to give voice to their concerns and to help them get the change they need. So to give voice but also to professionalise Aboriginal health as a discipline, that's what it's really about, and to give broader support so that it's not just Aboriginal people doing Aboriginal health.

— Gregory Phillips
Acknowledgements: We acknowledge the vision, time and efforts of all those who have contributed to the Indigenous Health Curriculum Project and the development of the LIME Network, including Reference Group members, Steering Committee members, Working Group members, Medical Deans Australia and New Zealand, secretariat staff and those who have had an interest and involvement in Indigenous health and education. The LIME Network is hosted by Onemda VicHealth Koori Health Unit, at the Melbourne School of Population and Global Health, University of Melbourne.

Competing interests: Shaun Ewen is Director of the LIME Network and a current Reference Group member. Margo Collins, Odette Mazel and Caitlin Ryan are or have been employed to work on the LIME Network program. Louise Lawler is a former LIME Reference Group member.

1 Rasmussen L. Towards reconciliation in Aboriginal health: initiatives for teaching medical students about Aboriginal issues. Melbourne: VicHealth Koori Health Research and Community Development Unit, 2001: 23.

2 House of Representatives Standing Committee on Aboriginal Affairs. Aboriginal health. Canberra: Australian Government Publishing Service, 1979.

3 National Aboriginal Health Strategy Working Party. A national Aboriginal health strategy. Canberra: Department of Aboriginal Affairs, 1989.

4 Johnston E. Royal Commission into Aboriginal Deaths in Custody. National report. Canberra: Australian Government Publishing Service, 1991.

5 Bringing them home: national inquiry into the separation of Aboriginal and Torres Strait Islander children from their families. Sydney: Human Rights and Equal Opportunity Commission, 1997.

6 Thomas DP. Reading doctors' writing: race, politics and power in Indigenous health research 1870-1969. Canberra: Australian Institute of Aboriginal and Torres Strait Islander Studies, 2004

7 Australian Bureau of Statistics; Australian Institute of Health and Welfare. The health and welfare of Australia's Aboriginal and Torres Strait Islander peoples. Canberra: ABS and AlHW, 2008. (ABS Cat. No. 4704.0; AlHW Cat. No. IHW21.) http://www.ausstats.abs.gov.au/ausstats/subscriber.nsf/0/51B575E133A75C6DCA2574390014EDFE/ \$File/47040_2008.pdf (accessed Mar 2013).

8 Council of Australian Governments. National partnership agreement on closing the gap in Indigenous health outcomes. Canberra:COAG, 2009. http://www.federalfinancialrelations.gov.au/content/npa/health_indigenous/ ctg-health-outcomes/national_partnership.pdf (accessed Jun 2013).

9 New Zealand Ministry of Health. Tatau Kahukura: Maori health chart book. Wellington: Ministry of Health, 2010. http://www.health.govt.nz/nz-health-statistics/health-statistics-and-data-sets/maori-health-data-and-stats/ tatau-kahukura-maori-health-chart-book (accessed Jun 2013).

10 Anderson IPS. The knowledge economy and Aboriginal health development. Melbourne: University of Melbourne, 2008. http://www.onemda.unimelb.edu.au/knowledge-economy-and-aboriginal-health-development-iananderson (accessed Mar 2013).

11 Mazel O, Anderson I. Advancing Indigenous health through medical education. Focus Health Prof Educ 2011; 13 (1): 1-12.

12 Jones R, Pitama S, Huria T, et al. Medical education to improve Maori health. N Z Med J 2010; 123: 113-122.

13 Hays R. One approach to improving Indigenous health care through medical education. Aust J Rural Health 2002; 10:285-287.

14 Committee of Inquiry into Medical Education and Medical Workforce. Australian medical education and workforce into the 21st century (Doherty Report). Canberra: Australian Government, 1988.

15 Mobbs R. But I do care! Communication difficulties affecting the quality of care delivered to Aborigines. Med J Aust 1986; 144 Suppl:S3-S5.

16 Anderson I. Koori health in Koori hands: an orientation manual in Aboriginal health for health-care providers. Melbourne: Health Department of Victoria, 1988.

17 Gibson RJ. The Aboriginal health curriculum. In: Henry R, Byrne K, Engel C, editors. Imperatives in medical education: the Newcastle approach. Newcastle: University of Newcastle, 1997.

18 Teubner J, Prideaux D. An innovative medical school. J High Educ Policy Manag 1997; 19 (1): 21-26.

19 Undergraduate Rural Curriculum Conference. Second rural undergraduate curriculum conference report: Townsville 3-5 September 1996. Canberra: Australian Government Publishing Service, 1997.

20 National Rural Health Alliance. 4th National Rural Health Conference Proceedings; 1997 Feb 9-12; Perth. Canberra: NRHA, 1997. http://nrha.ruralhealth.org.au/conferences/? IntCatld=9 (accessed Mar 2013).

21 Garvey G, Brown N. Project of national significance final report: Aboriginal health, a priority for Australian medical schools. Newcastle: University of Newcastle, 1999.

22 Australian National Audit Office. The Aboriginal and Torres Strait Islander health program. (Audit Report No.13 Performance Audit.) Canberra: Department of Health and Aged Care, 1998.

23 Phillips G. Strategic framework for the inclusion of Indigenous health in core medical curricula and recruitment, retention and support strategies for Indigenous Australians in medical education. Melbourne: LIME Network, 2001.

24 Australian Government Department of Health and Ageing. Annual report 2002-03. Canberra: DoHA, 2003.

25 Phillips G. CDAMS Indigenous Health Curriculum Development Project: national audit and consultations report. (Discussion Paper No. 11.) Melbourne: VicHealth Koori Health Research and Community Development Unit, 2004

26 Phillips G. CDAMS Indigenous Health Curriculum Framework. Melbourne: VicHealth Koori Health Research and Community Development Unit, 2004.

27 Australian Medical Council. Assessment and accreditation of medical schools: standards and procedures. Canberra: AMC, 2006.

28 Phillips G. CDAMS Indigenous Health Curriculum Project: LIME Network discussion paper. Melbourne: LIME Network, 2005. http://www.limenetwork.net.au/files/lime/LIMEnetworkdiscussionpaper.pdf (accessed Mar 2013).

29 University of Melbourne; Murrup Barak, Melbourne Institute for Indigenous Development. In partnership with Rio Tinto. http://www.murrupbarak.unimelb.edu.au/content/pages/partnership-rio-tinto (accessed Mar 2013).

30 Centre for the Study of Higher Education, University of Melbourne. Norman Curry Award for Innovation and Excellence in Educational Programs. http://www.cshe.unimelb.edu.au/prof_dev/awards/UoMawards/NC.html (accessed Mar 2013).

31 LIME Network. LIME good practice case studies. Melbourne: University of Melbourne, 2012.

32 Australian and New Zealand Association for Health Professional Educators, LIME Network, editors. Focus Health ProfEduc 2011; 13 (1): 1-101.

33 Australian Indigenous Doctors' Association; Medical Deans Australia and New Zealand. Aboriginal and Torres Strait Islander medical student numbers jump [media release]. 21 Aug 2012. http://www.aida.org.au/pdf/news/0012.pdf (accessed Mar 2013).

34 Australian Indigenous Doctors' Association; Medical Deans Australia and New Zealand. A review of the implementation of the Indigenous Health Curriculum Framework and the Healthy Futures Report within Australian medical schools. 2012. http://www.medicaldeans.org.au/wp-content/uploads/20120412MedicalDeans-AIDA-Review-Final-Report.pdf (accessed Mar 2013). 